\title{
ESTUDO DE CASO PRELIMINAR DA POLUIÇÃO DA SUB BACIA DO CÓRREGO DO CERCADINHO, BELO HORIZONTE - MG
}

Daniele Keesem Caetano - daniele.caetano@live.com

Centro Universitário de Belo Horizonte

Elisa Carneiro Alonso- elisa20alonso@ hotmail.com

Centro Universitário de Belo Horizonte

Filipe Leonardo de Sousa- filipe_gpod@ hotmail.com

Centro Universitário de Belo Horizonte

Inês Maria Lara da Costa- inesmlcosta@ hotmail.com

Centro Universitário de Belo Horizonte

Thâmara Mércia Souza Carvalho - c.s.m.thamara@hotmail.com

Centro Universitário de Belo Horizonte

Yuri Lorran Braga Cunha - yuri.lorran@ hotmail.com

Centro Universitário de Belo Horizonte 


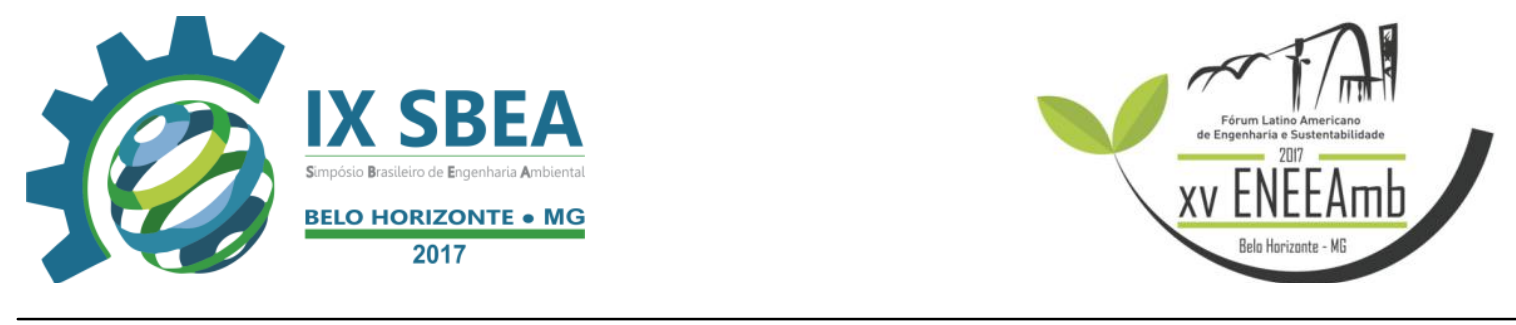

\section{RESUMO}

Este artigo apresenta um estudo de caso realizado na sub bacia hidrográfica do córrego do Cercadinho, localizada em Belo Horizonte/MG, visando futuramente à implantação de programas que reduzam a carga de poluição existente no córrego do Cercadinho e seus afluentes, promovendo a recuperação da área, bem como promover melhor qualidade de vida para os munícipes que moram às margens e no entorno do mesmo.

\section{INTRODUÇÃO/OBJETIVO}

A população mundial atual, segundo dados de 2015 da Organização das Nações Unidas (ONU), é de 7,3 bilhões de pessoas, e tende a crescer cerca de 53\% até 2100. Tal crescimento populacional, somado ao processo acelerado de urbanização, algumas vezes, fazem com que as cidades cresçam desordenadamente e sem um adequado planejamento, acarretando em consequências negativas, como, por exemplo, o aumento da poluição, e, sobretudo, a geração de resíduos sólidos e descarte de efluentes domésticos de forma inadequada, devido à falta de saneamento básico em muitas regiões.

Essa carga poluidora lançada sobre as águas pode ocasionar a eutrofização de corpos hídricos, tendo em vista a presença de nutrientes em grandes quantidades, ocasionando elevadas quantidades de algas e plantas aquáticas, além de odores e sabores desagradáveis e mortandade de peixes e outros animais, o que favorece o surgimento de doenças de veiculação hídrica, tendo em vista o comprometimento da qualidade das águas, que, muitas vezes são destinadas ao abastecimento público (POÇAS, 2015). Visando amenizar tais impactos ambientais, surgem algumas propostas para tratamento de esgotos e águas residuárias.

Uma das tecnologias que vem se destacando atualmente, é a implantação de wetlands construídos, baseadas no conceito dos wetlands naturais, ecossistemas de áreas úmidas que utilizam a filtração física, química e biológica na transformação de poluentes presentes em esgotos sanitários e harmonizando a relação homem-natureza (MAZONETTO, 2011; YAMAMOTO; CANALI, 2012; WEBER; PRADO; KAICK, 2015). Os wetlands construídos são sistemas artificialmente projetados que utilizam 
plantas aquáticas em substratos como areia ou cascalhos, que atuam como elementos filtrantes e favorecem a produção de biofilmes que, por sua vez, agregam microrganismos e tratam águas residuárias através de processos biológicos, químicos e físicos (SOUSA et al; 2004; MAZONETTO, 2011; YAMAMOTO; CANALI, 2012; WEBER; PRADO; KAICK, 2015).

A implantação de wetlands construídos, é viável, inclusive para complemento das etapas de Estações de Tratamento de Efluentes (ETE), conforme os estudos de Sousa et al. (2004) e Weber et al. (2015). Yamamoto e Canali (2012) salientam a importância das wetlands para melhoria da qualidade das águas e redução de carga poluidora em bacias hidrográficas.

Asub bacia do córrego Cercadinho, afluente do ribeirão Arrudas, está inserida na região Oeste do município de Belo Horizonte/MG, e possui área bastante poluída, com deficiência de mata ciliar egrande deposição de resíduos sólidos urbanos e de construção civil ao longo de seus afluentes.

Neste sentido, a partir dos resultados obtidos, este trabalho visa propor soluções e medidas que visam reduzir a carga de poluição presente na região e promover melhorias na biota e qualidade de vida para a população local, citando como exemplo, a implantação de wetlands construídos na sub bacia estudada.

\section{METODOLOGIA}

Através de visitas à bacia do Cercadinho, conversas com a comunidade e análises laboratoriais de água, foram constatadas algumas melhorias a serem feitas na bacia hidrográfica em questão para o retorno da qualidade ambiental e qualidade de vida dos ribeirinhos.

A caracterização visual e relação com a comunidade foram realizadas no curso dos córregos Ponte Queimada e Cercadinho em 10 de abril de 2017, através de caminhada ao logo dos afluentes da bacia que possuem comunidade ribeirinha e registrando através de anotações e fotografias os problemas visualizados, bem como os ditos pelos munícipes para posterior análise crítica.

As análises físicas e químicas de amostras da água do córrego Ponte Queimada da bacia, realizadas em 18 de maio de 2017 no parque Aggeo Pio Sobrinho, foram 
coletadas em dois pontos onde a comunidade não tem acesso (Área de Preservação Permanente - APP) e um ponto na área aberta à comunidade. Através do método do Alfakit, seguindo as seguintes etapas:

Primeiro ponto

- Coleta de material em frasco coletor de $250 \mathrm{~mL}$ com tampa às 08:44 horas e medição de pH no local.

- Análise realizada em laboratório às 10:24 horas, observando os parâmetros: Oxigênio Dissolvido - OD; Amônia Indotest; Nitrato método NTD; Nitrito método NTD; e Ortofosfato.

Segundo ponto

- Coleta de material em frasco de $250 \mathrm{~mL}$ com tampa às 09:22 horas e medição de pH no local.

- Análise realizada em laboratório com início às 10:45 horas, observando os parâmetros: Oxigênio Dissolvido - OD; Amônia Indotest; Nitrato método NTD; Nitrito método NTD; e Ortofosfato.

Terceiro ponto

- Coleta de material em frasco de $250 \mathrm{~mL}$ com tampa às 09:32 horas e medição de pH no local.

- Análise realizada em laboratório às 11:03 horas, observando os parâmetros: Oxigênio Dissolvido - OD; Amônia Indotest; Nitrato método NTD; Nitrito método NTD; e Ortofosfato.

Para os parâmetros analisados foram seguidas as metodologias do Alfakit:

Oxigênio Dissolvido - OD: Encher a cubeta pequena com a amostra derramando pelas paredes com cuidado, adicionar uma gota do reagente 01, fechar evitando bolhas e agitar; adicionar duas gotas do reagente 02, fechar evitando bolhas e agitar; adicionar uma medida rasa (pazinha $\mathrm{n}^{\circ} 2$ ) do reagente 03 e agitar, abrir a cubeta, posicioná-la sobre a cartela e fazer a comparação colorimétrica, anotar o resultado.

Amônia indotest: Transferir $5 \mathrm{~mL}$ da amostra para a cubeta, adicionar três gostas do reagente 01 , fechar e agitar; adicionar três gostas do reagente 02 , fechar e agitar; adicionar três gostas do reagente 03, fechar e agitar; aguardar dez 


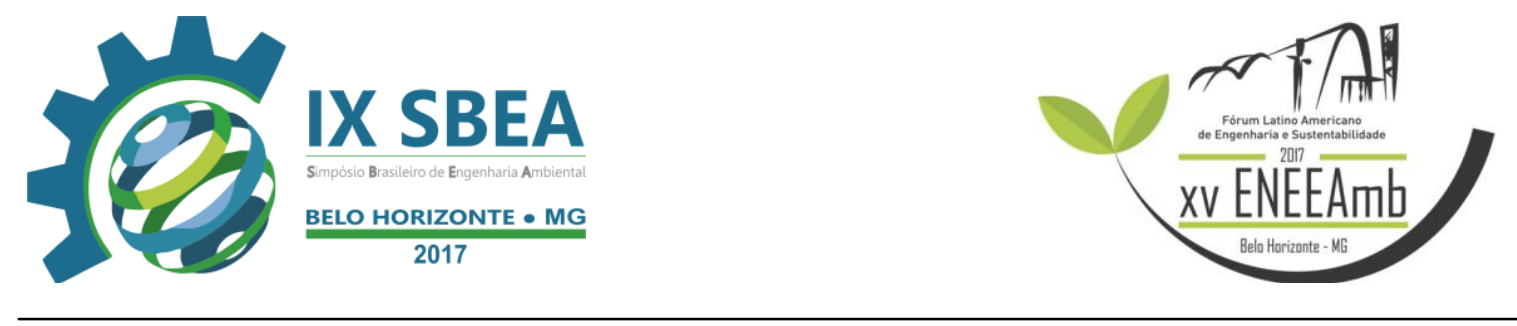

minutos, abrir a cubeta, posicioná-la sobre a cartela e fazer a comparação colorimétrica, anotar o resultado. (Lembrando que a toxicidade da Amônia varia de acordo com o $\mathrm{pH}$ )

Nitrato método NTD: Transferir $5 \mathrm{~mL}$ da amostra para a cubeta, adicionar uma medida (pazinha $\mathrm{n}^{\circ} 1$ ) do reagente 01, fechar e agitar até dissolver; adicionar uma medida (pazinha $\mathrm{n}^{\circ} 1$ ) do reagente 02, fechar e agitar até dissolver; adicionar duas gotas do reagente 03 agitar bem, fechar aguardar quinze minutos, abrir a cubeta, posicioná-la sobre a cartela e fazer a comparação colorimétrica, anotar o resultado.

Nitrito método NTD: Transferir $5 \mathrm{~mL}$ da amostra para a cubeta, adicionar uma medida (pazinha $\mathrm{n}^{\circ} 1$ ) do reagente 01 , fechar e agitar até dissolver; adicionar uma medida (pazinha $\mathrm{n}^{\circ} 1$ ) do reagente 02 , fechar e agitar até dissolver; adicionar duas gotas do reagente 03 agitar bem, fechar aguardar quinze minutos, abrir a cubeta, posicioná-la sobre a cartela e fazer a comparação colorimétrica, anotar o resultado.

Ortofosfato: Transferir $5 \mathrm{~mL}$ da amostra para a cubeta, adicionar cinco gotas do reagente 01 , fechar e agitar; adicionar uma medida do reagente 02 (pazinha $\mathrm{n}^{\circ} 1$ ), fechar e agitar; aguardar dez minutos, abrir a cubeta, posicioná-la sobre a cartela e fazer a comparação colorimétrica, anotar o resultado.

\section{RESULTADOS E DISCUSSÃO}

Através das caminhadas nas comunidades ribeirinhas, foi possível perceber o depósito de resíduos sólidos da construção civil, resíduos sólidos urbanos, despejo irregular de efluentes domésticos e ocupação irregular na mata ciliar dos afluentes da bacia do cercadinho. Os moradores relatam surgimento de pragas urbanas, pequenos alagamentos em períodos chuvosos, além de constantes deslizamentos.

Ao longo do curso do Ponte Queimada, pode-se observar forte odor característico de excesso de matéria orgânica proveniente de efluentes domésticos, coloração esverdeada indicando a presença de algas, além de turbidez. No curso do Córrego cercadinho são encontradas as mesmas características, porém, intensificadas. 


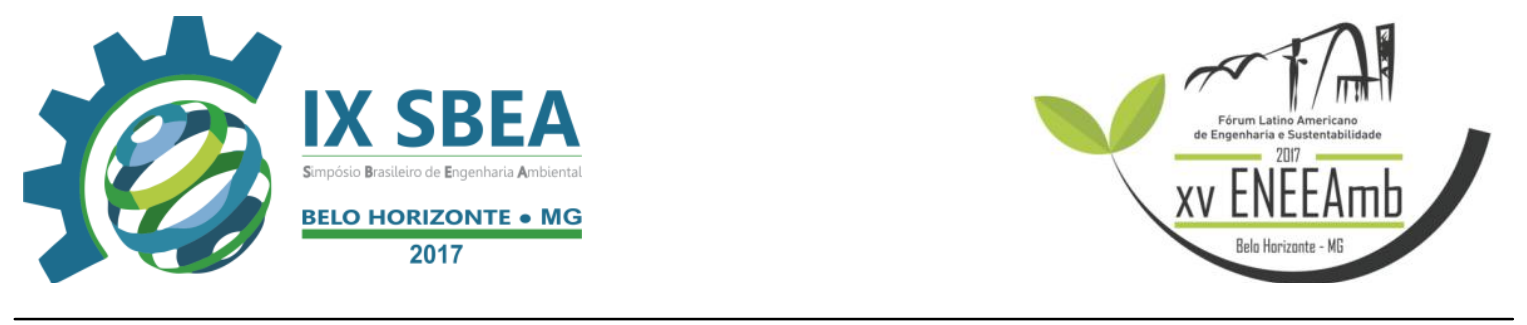

Por meio de análises utilizando o método AlfaKit, observou-se alteração nos padrões de qualidade da água (tabela 1).

Tabela 1 - Resultados das análises físico-químicas

\begin{tabular}{|c|c|c|c|c|}
\hline Parâmetro $\quad$ Amostra & 01 & 02 & 03 & ParâmetrosTeóricos \\
\hline $\mathrm{OD}\left(\mathrm{mg} \mathrm{L}^{-1} \mathrm{O}_{2}\right)$ & 8 & 9 & 7 & não inferior a 6 \\
\hline $\begin{array}{l}\text { Amônia indotest } \\
\left(\mathrm{mg} \mathrm{L}^{-1} \mathrm{~N}-\mathrm{NH}_{3}\right)\end{array}$ & 0,10 & 0,0 & 0,25 & 1,5 \\
\hline $\begin{array}{l}\text { Nitrato MétodoNTD } \\
\qquad\left(\mathrm{mg} \mathrm{L}^{-1} \mathrm{~N}-\mathrm{NO}_{3}\right)\end{array}$ & 0,1 & 0,1 & 0,1 & 10,0 \\
\hline $\begin{array}{l}\text { Nitrito MétodoNTD } \\
\qquad\left(\mathrm{mg} \mathrm{L}^{-1} \mathrm{~N}-\mathrm{NO}_{2}\right)\end{array}$ & 0,01 & 0,01 & 0,03 & 1,0 \\
\hline $\begin{array}{l}\text { Ortofosfato } \\
\left(\mathrm{mg} \mathrm{L}^{-1} \mathrm{PO}_{4}\right)\end{array}$ & 0,0 & 0,75 & 0,75 & entre 0,056 e 0,084 \\
\hline $\mathrm{pH}$ & 6 & 7 & 6 & entre6 e 9 \\
\hline Turbidez UNT & $<50$ & $<50$ & $<50$ & até 40 \\
\hline
\end{tabular}

Os resultados foram submetidos a comparações de parâmetro de qualidade das águas doces do tipo classe especial e classe1 de acordo com o que a resolução CONAMA 357/2005 estabelece.

Os pontos 1,2 e 3 analisados apresentam discrepâncias comparadas ao parâmetro de qualidade da água nos itens:amônia, nitrito e nitrato. No ponto 2 apresenta ausência total de amônia e essas pequenas quantidades presentes nos outros pontos indicam que a água está livre de poluição.

Os pequenos níveis de íon nitrato na água indicam que naqueles pontos a chance de contaminação é pequena. 


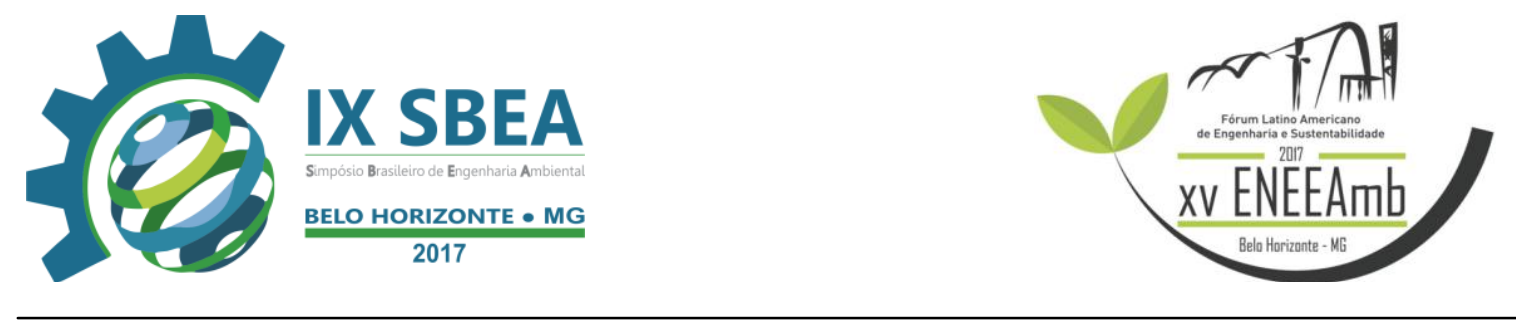

Somente o ponto 1 possuí $0,0 \mathrm{mg} \mathrm{\textrm {L } ^ { - 1 }} \mathrm{PO}_{4}$ de ortofosfato na sua amostra e está fora dos parâmetros. Sendo assim, indica ausência de eutrofização artificial, o que implica na quantidade de nutrientes para algas e plantas aquáticas.

Todos os outros parâmetros então dentro ou próximos dos valores estabelecidos e apresentam normalidade. A cor e odor aparentemente apresentaram inalterados no nível natural do corpo de água e odor também não perceptível.

Os pontos analisados encontrados em locais de preservação, aparentemente não possuem acesso à população, mas apresenta necessidade de diagnóstico ambiental para que conclua o motivo das alterações nesse corpo hídrico.

\section{CONCLUSÕES/RECOMENDAÇÕES}

Mediante a visita ao parque Aggeo Pio Sobrinho foi possível observar pontos potenciais de poluição, que possivelmente poderiam afetar a qualidade da água do córrego local. Após a análise e observação dos resultados obtidos, segundo parâmetros padrão de qualidade de água, as amostras coletadas apresentaram divergências em relação ao padrão esperado em alguns itens, em outros mostrou-se dentro do esperado.

Logo, conclui-se que, de fato os pontos avaliados necessitam de um tratamento adequado para haver a padronizar da água coletada nestes pontos. Seria também de suma importância à continuidade deste trabalho, havendo então uma posterior visita ao parque,com a finalidade de realizar novas coletas e consequentemente análises para a avaliação de outros possíveis pontos de poluição e resíduos causadores dessa poluição, abrangendo assim as possibilidades de tratamento da bacia.

\section{REFERÊNCIAS BIBLIOGRÁFICAS}

MAZONETTO, C. Tratamento natural de esgoto. Infraestrutura urbana: projetos, custos e construção. Ed. 14, mai. 2012. Disponível em: < 


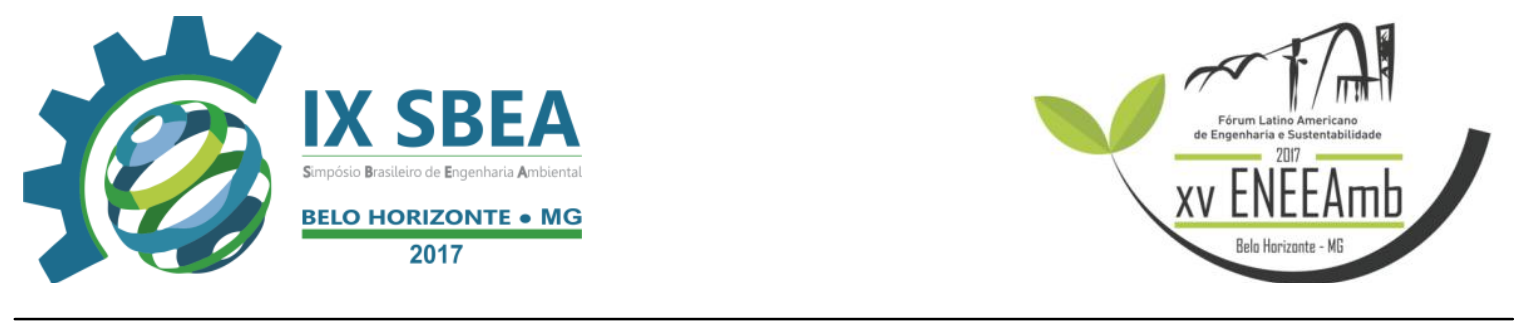

http://infraestruturaurbana.pini.com.br/solucoes-tecnicas/14/artigo256157-1.aspx>. Acesso em 20 mai 2017.

MMA - Ministério do Meio Ambiente. Resolução CONAMA no 357.17 de Março de 2005. Publicada no DOU no 053, de 18 de Março de 2005, págs. 58-63. Disponível em <http://www.mma.gov.br/port/conama/res/res05/res35705.pdf>. Acesso em: 01 Junho de 2017.

ONU - Organização das Nações Unidas. Perspectivas da população mundial: a revisão de 2015. Relatório anual da ONU. 2015.

POÇAS, C. D. Utilização de tecnologia de wetlands para tratamento terciário: controle de nutrientes. São Paulo, 109 p., 2015. Dissertação (Mestrado) - Curso de Ciências. Faculdade de Saúde Pública da Universidade de São Paulo.

CONSELHO NACIONAL DO MEIO AMBIENTE - CONAMA. Resolução $n^{\circ}$ 357, de 18 de março de 2005. Dispõe sobre a classificação dos corpos de água e diretrizes ambientais para o seu enquadramento, bem como estabelece as condições e padrões de lançamento de efluentes, e dá outras providências. Disponível em: http://www.mma.gov.br/port/conama/legiabre.cfm?codlegi=459. Acesso em: 07 mai. 2017.

SOUSA, J. T.; HAANDEL, A. V.; LIMA, E. P. C.; HENRIQUE, I. N. Utilização de wetland construído no pós-tratamento de esgotos domésticos pré-tratados em reator UASB. Eng. Sanit. Ambient. Rio de Janeiro, v. 9, n. 4, p. 285-290, out/dez. 2004.

WEBER, C. F.; PRADO, M. R.; KAICK, T S. V. Dimensionamento de wetlands construídas em sistemas individuais de tratamento de esgoto sanitário. In: SIMPÓSIO BRASILEIRO SOBRE WETLANDS CONSTRUÍDOS, 2., Curitiba. Anais... Curitiba: UFTPR - Auditório, 2015.

YAMAMOTO, C. R. G.; CANALI, N. E. Importância das wetlands para a qualidade das águas na região metropolitana de Curitiba - PR. Revista Geografar, Curitiba, v. 7, n.1, p. 161-189, jun. 2012. 